\title{
Quiero ser buérfano: Psicoanálisis, autoridad, y cultura de izquierda en el '68 italiano
}

I want to be an orphan: Psychoanalysis, authority, and culture of the left in the '68 Italian

\author{
Mauro Pasqualini*
}

\begin{abstract}
Resumen: Las intensas movilizaciones en torno al año 1968 en Italia incentivaron la presencia social del discurso psicoanalítico. El artículo se centra en escritos coyunturales de la periodista, novelista y cineasta Lorenza Mazzetti (1927-), y artículos más acabados del psicoanalista Elvio Fachinelli (1928-1989). A través de estos ejemplos, se busca ilustrar los diversos usos del psicoanálisis al interior del '68 italiano. Fundamentalmente, se busca resaltar la compleja apropiación del psicoanálisis, que era invocado como saber experto y al mismo tiempo celebrado como recurso de crítica cultural y política.
\end{abstract}

Palabras clave: Italia, Historia siglo XX; 1968; Psicoanálisis.

The intense mobilizations around the year 1968 in Italy elicited psychoanalysis' social relevance. The article focuses on discrete pieces by the journalist, novelist, and filmmaker Lorenza Mazzetti (1927-), and on articles by psychoanalyst Elvio Fachinelli (19271989). Through these examples, the article illustrates the uses of psychoanalysis during the Italian 1968 and its immediate aftermath. These examples show the complex appropriation of psychoanalysis during 1968, since it was invoked as an expert knowledge while also celebrated as a resource for cultural and political criticism.

Keywords: Italy, History XX century; 1968; Psychoanalysis

Recibido: 28 agosto 2018 Aceptado: 17 octubre 2018

\section{Introducción}

Los movimientos del '68 europeo fomentaron novedosas prácticas de movilización y protesta, además de promover formas alternativas de organización, o plantear la politicidad de áreas de la vida privada, familiar, e interpersonal. Al mismo tiempo, fueron también receptores e inspiradores de teorías innovadoras, impulsaron nuevas lecturas de viejos cuerpos doctrinarios, o estimularon nuevas formas de pensar la relación entre teoría social y activismo político. Quienes rastrean sus "orígenes ideológicos" o la "orientación cognitiva" que impregnaron la protesta no dejan de apuntar a influencias y estímulos variados y heterogéneos, tales como las vanguardias artísticas al estilo de los Situacionistas, los autores de la Nueva Izquierda como Herbert Marcuse, Theodor Adorno o Max Horkheimer, teóricos marxistas de entreguerras (Antonio Gramsci, Karl Korsch, George Lukács, Rosa Luxemburgo), además de

\footnotetext{
* Argentino. Historiador, especializado en historia europea contemporánea. Investigador asistente en CONICET (Argentina). Email: mpasqu2@gmail.com
} 
políticos e intelectuales asociados a los procesos de descolonización. ${ }^{1}$ Sin duda, la expansión de la matrícula universitaria, y el emerger de nuevas profesiones en la educación, la salud mental, las ciencias sociales y las humanidades fueron también un estímulo para la circulación de novedades culturales. Finalmente, el crecimiento del mercado editorial y nuevas posibilidades de publicación y acceso a libros más baratos fueron un elemento determinante para esta renovación y expansión del paisaje cultural que enmarcó al '68.'

Tanto los autores entronizados por la protesta estudiantil o juvenil, como los múltiples paradigmas usados para descifrarla por parte de comentaristas o simpatizantes implicaron una renovación teórica e intelectual. Tal vez, una de las esferas donde esto es más visible es en el ámbito de la salud mental. Para el caso del '68 italiano, de hecho, son muchas las referencias a la relación entre la protesta estudiantil y la corriente de la "anti-psiquiatría" inspirada por el psiquiatra Franco Basaglia. ${ }^{3}$ Aunque este vínculo es usualmente mencionado al analizar esta época, lamentablemente no existe todavía un análisis similar o más detallado de la relación entre la movilización social y cultural de esos años y otra corriente en auge en ese momento: el psicoanálisis. Se trata de una verdadera carencia puesto que los debates, los reclamos, y las características de las acciones iniciadas sobre todo por el movimiento estudiantil invitaron, provocaron, y movilizaron el uso del psicoanálisis. Como recupera el historiador Paul Ginsborg, una de las frases que mejor podría resumir el espíritu de revuelta generacional en torno al '68 era el eslogan "Quiero ser huérfano." 4 Como parte de los tantos grafitis escritos en las paredes de esos meses, resumía sin ambigüedad el conflicto generacional, pero también el componente de jocosa irreverencia desde la cual se buscaba desacralizar y socavar las jerarquías y formas de autoridad tradicionales y más arraigadas. Al mismo tiempo, era también una expresión que ponía la dimensión edípica al centro de cualquier análisis que se quisiera hacer del movimiento, así como convocaba al psicoanálisis al diálogo en cuanto técnica que estudiaba las formas de internalización e introyección de normas, valores, y figuras de autoridad.

En las siguientes páginas vamos a hacer una aproximación introductoria al estudio de la relación entre el psicoanálisis y el '68 italiano. Para eso, vamos a repasar los escritos de la periodista, escritora, y directora cinematográfica Lorenza Mazzetti (1927-1989) en su columna de consejos personales en el semanario comunista Vie Nuove. Si bien no era una psicoanalista practicante, desde hacía varios años la columna de Mazzetti recurría a nociones psicoanalíticas en sus consejos a sus lectores, tarea en la que era asistida por psicoanalistas que colaboraban con ella. ${ }^{5}$ Como veremos, en la coyuntura de la movilización estudiantil, Mazzetti desplegó una argumentación fuertemente psicoanalítica para establecer un diálogo crítico, nada condescendiente, con algunas iniciativas de los estudiantes. Por otra parte, algunas de las influencias que tomó para su reflexión, consistían de autores

\footnotetext{
1 Para una panorámica del '68 en Europa y EEUU ver Tony Judt, Postwar: A History of Europe since 1945, Nueva York, Penguin Press, 2005, 390-421; Geoff Eley, Forging Democracy: The History of the Left in Europe, 1850-2000, Nueva York, Oxford University Press, 2002, pp. 341-365; Martin Klimke y Joachim Scharloth (eds), 1968 in Europe: A History of Protest and Activism, Nueva York, Palgrave, 2008; Ronald Fraser (ed), 1968: A Student Generation in Revolt, Nueva York, Pantheon Books, 1988; y Donald Sasoon, One Hundred Years of Socialism: The West European Left in the Twentieth Century, Londres, Fontana, 1993, pp. 383-406. Para una vision del caso francés que incorpora la memoria de las últimas décadas, ver Kristin Ross, May '68 and its Afterlives, Chicago, University of Chicago Press, 2002.

2 Para el rol del mercado editorial, ver Ben Mercer, "The Paperback Revolution: Mass-circulation of Books and the Cultural Origins of 1968 in Western Europe," Journal of the History of Ideas, vol 72, n 4 (Octubre 2011); y Ross, op. cit, pp. 80-90. Para Italia ver también Robert Lumley, States of Emergency: Cultures of Revolt in Italy from 1968 to 1978, Londres, Verso, 1990, $39-40$.

3 Ver por ejemplo Michael Donnelly, The Politics of Mental Health in Italy, Londres, Routledge, 1992; o Paul Ginsborg, A History of Contemporary Italy. Society and Politics, 1943-1988, Nueva York, Palgrave, 2003, 302-305.

${ }_{4}^{4}$ Ginsborg, op. cit, 304-305. El eslógan está tomado del recuerdo de una protagonista. La reproducción completa es: "Por lejos, el mejor graffiti sobre las paredes de mi universidad, lo recuerdo totalmente claro, fue este: 'quiero ser huérfano.' Acordé con él, lo fotografié, llevé un poster de él a mi casa; fue el eslogan que más me gustó.” La frase está tomada de las entrevistas sobre el '68 de la historiadora Luisa Passerini, Autoritratto di gruppo, Florencia, Giunti, 1988,p. 46.

5 Sobre Mazetti, la revista Vie Nuove y el psicoanálisis, ver Mauro Pasqualini, "Psychoanalysis to the People! Alienation, Anguish, and the Unconscious in a Review of the Italian Left, 1961-1969," Psychoanalysis and History, 15:1, Enero 2013 , $45-67$.
} 
muy vinculados a la cultura contestataria de la época. En segundo lugar, vamos a repasar las intervenciones y análisis desarrollados por el psicoanalista Elvio Fachinelli (1928-1989). Formado en el seno de la Sociedad Psicoanalitica Italiana [SPI], pero acusando un amplio radio de influencias e intereses, el perfil de Fachinelli difiere en muchos aspectos del de Mazzetti. La mayoría de sus intervenciones, de hecho, tuvieron lugar en la revista Quaderni Piacentini, considerada una de las expresiones más acabadas de la Nueva Izquierda en Italia. Su perfil era el de un psicoanalista practicante que vinculaba su labor clínica con la intervención pública.

Analizando estos dos casos, nos interesa ver el lugar complejo del psicoanálisis en la coyuntura del '68. Fundamentalmente, la dificultosa búsqueda para encontrar una situación intermedia entre la supuesta neutralidad del observador desinteresado y la participación del activista comprometido. Al desplegar sus reflexiones sobre las movilizaciones del momento, de hecho, los autores en cuestión debían mantener el equilibrio entre múltiples presiones: por un lado, balancear su posición entre aquellos aspectos del movimiento estudiantil que les parecían valiosos y los llamaban a participar activamente, de aquellos que veían como problemáticos. En segundo lugar, debían reflexionar sobre su propia mirada, y la manera en que estaban reproduciendo o no una supuesta actitud disciplinaria normativa. En este sentido, el psicoanálisis como marco de observación se transformó en sujeto y objeto del '68. Fue convocado como un espacio desde donde analizar los sucesos en cuestión, pero al mismo tiempo fue cuestionado y sometido a un proceso de re-definición. Los dos casos aquí analizados son valiosos porque nos permiten dar cuenta de esta encrucijada.

\section{El '68 en Italia}

La oleada de protesta estudiantil y juvenil en torno al año 1968 tuvo un carácter transnacional. Sin embargo, para los fines de este artículo conviene centrarnos en algunas especificidades del caso italiano, fundamentalmente en lo que hace a su intensidad, a su extensión temporal, la amplitud de demandas acicateando las movilizaciones, y la esfera cultural que la enmarcó. La conjunción de miradas y actitudes críticas en torno a la educación y los valores y prácticas que la circundaban, de hecho, encontraban un espacio particularmente explosivo en el sistema educativo italiano. Estimulados por legislación respectiva, además de nuevas expectativas sociales, los estudiantes secundarios se duplicaron entre 1959 y 1969, mientras que los universitarios pasaron de 268000 en 1960 a 450000 en 1968 (las mujeres eran un tercio de ese total, si bien se habían duplicado en términos absolutos). Se trató de un proceso que se dio en muchos otros países, pero que en Italia se experimentó de manera particularmente acelerada e intensa. La rápida masificación del sistema no estuvo acompañada de reformas infraestructurales adecuadas, ni por la expansión de la planta docente, ni por la renovación de los métodos de enseñanza. Por otro lado, el porcentaje de graduación de las universidades era solo del $44 \%$, lo cual indica la falta de estrategias de retención de estudiantes, o de sistemas de becas para los más humildes, lo que agregaba una importante fuente de frustración dentro del marco de la masificación de la educación media y superior. ${ }^{6}$

La expansión del sistema educativo, por otro lado, funcionó como una caja de resonancia de diversas formas de malestar. Uno de los episodios que anticiparon la revuelta estudiantil, de hecho, fue la publicación del libro del cura católico Lorenzo Milani, Cartas a una maestra normal. Se trataba de una recolección de cartas de estudiantes de primaria de un pequeño pueblo de la Toscana, que revelaban el carácter de clase del sistema educativo, sus formas de exclusión, y la manera en que se privilegiaba lo individual sobre lo colectivo y comunitario. El libro tuvo una repercusión enorme, y se volvió un texto fundamental de la movilización de esos meses. ${ }^{7}$ En otros casos, el malestar se hacía sentir en otras

${ }_{6}^{6}$ Ginsborg, op. cit, 299-301; Lumley, op. cit, 49-62. Para una panorámica europea sobre el mismo proceso, ver Judt, op. cit, 390-395.

${ }^{7}$ Sobre la influencia de Milani, ver Lumley, op. cit, 82-83, 126-127; y Ginsborg, op. cit, 300-301. 
esferas. Uno de los hechos más trascendentes anticipando el ' 68 fue el de los/as estudiantes secundarios del Liceo Parini, de Milan, quienes, en 1966 publicaron una encuesta en la revista estudiantil La Zanzara sobre la situación de la mujer, que incluía las ideas de las estudiantes en favor de la educación sexual, la anti-concepción, el divorcio, y el sexo pre-matrimonial. La publicación generó enseguida la reacción escandalizada de los sectores más conservadores del sistema educativo y la acusación a los redactores por el delito de obscenidad, aparte de dividir a la opinión pública en torno al tema. ${ }^{8}$ Cuestiones referentes a la ruptura con normas de discreción y decoro propias de la generación anterior, de hecho, se pueden encontrar en el estilo mismo del activismo estudiantil posterior. Como han comentado muchos observadores, entre diciembre del ' 67 y febrero del ' 68 , es decir, las semanas más intensas de la movilización universitaria, se vivió una verdadera revolución en cuanto al abandono de viejas formas de respetabilidad, y el remplazo de sacos, camisas, corbatas, vestidos y maquillaje, por jeans, pelo largo, barba, pullovers y botas. El corte generacional se puede percibir también en la falta de solidaridad de las autoridades y el cuerpo docente, que se mantuvieron entre hostiles y distantes a los estudiantes. ${ }^{9}$

La cronología de los acontecimientos más álgidos del '68 es también reveladora de la intensidad y amplitud del malestar estudiantil. La primera universidad en experimentar una oleada de ocupaciones y asambleas ya a principios de 1966 fue la Universidad de Trento, que se había fundado pocos años antes como parte de un proyecto de crear una elite dirigente moderna por parte de políticos y administradores vinculados a la Democracia Cristiana (el partido gobernante). Meses después, en noviembre de 1967, ocurrió algo similar en la Universidad Católica de Milán (un bastión católico conservador), cuyos dirigentes observaron espantados como los estudiantes tomaban la universidad en respuesta a un aumento del $50 \%$ de la cuota, para pasar luego a generar nuevos planteos y demandas. ${ }^{10}$ Recién a fines de ese mes llegó el turno de la Universidad de Turín (estatal), y desde entonces y hasta febrero del ' 68 , la protesta se expandió hasta las regiones más remotas del sur. Si bien el tema unificador era el rechazo a una serie de reformas del ministerio (que buscaban re-introducir exámenes de admisión, y establecer jerarquías en torno a los títulos), las demandas pronto trascendieron lo meramente legislativo, para pasar a denunciar toda una lógica política detrás de estas reformas. A los estudiantes universitarios también se sumaron los secundarios, con su propia agenda de temas en torno a mayor participación en las decisiones, reformas pedagógicas anti-autoritarias, y mayor igualdad en el acceso a la educación. ${ }^{11}$

Finalmente, la intensidad de la violencia represiva también fue una característica distintiva del caso italiano. Un momento crucial al respecto fue la llamada "Batalla de Valle Giulia," cuando los estudiantes resistieron el desalojo de la Universidad de Roma por parte de la policía en marzo del '68. Desde entonces, los enfrentamientos se hicieron crónicos, y parte intrínseca de las formas de protesta. De hecho, algunos cálculos estiman que entre abril de 1968 y julio de 1970 hubo alrededor de 28 estudiantes muertos por enfrentamientos con la policía. ${ }^{12}$ Pero estos hechos, a su vez, son solo un aspecto del accionar represivo. A partir de diciembre de 1969, cuando una bomba en Piazza Fontana, en Milán, dejó 16 víctimas fatales, el accionar de grupos de extrema derecha o fascistas en consonancia con elementos estatales pasó a primer plano. Esto generó una situación de creciente inseguridad y terror tendiente a crear un clima legitimante para un giro autoritario y represivo en la sociedad italiana. Esta actitud, denominada “estrategia de la tensión” estimuló al mismo tiempo la emergencia de grupos

\footnotetext{
8 Sobre este tema, ver Diego Giachetti, Anni Sessanta Comincia la Danza. Giovani, Capeloni, Studenti ed Estremisti negli Anni della Contestaz̧ione, Pisa, BFS, 2002, 45-50, quien advierte que si bien el caso fue el más vistoso, muchas otras revistas estudiantiles secundarias hicieron desafíos similares en esos meses.

9 Para descripciones de este proceso, ver Giachetti, op. cit, 173-175; y Ginsborg, op. cit, 303-304.

10 Sobre el rol del giro radical dentro del catolicismo, ver Lumley, op. cit, 77-86. Para una cronología de eventos del movimiento estudiantil, ver Jan Kurz y Marica Tolomeli, "Italy," en Klimke y Scharloth (eds), op. cit, 87-89.

${ }^{11}$ Lumley, op cit, 94-98.

12 Lumley, op. cit, 68, 75. Pero antes de estas fechas, el estudiante socialista Paolo Rossi había resultado asesinado durante una protesta en abril de 1966. Ver Kurz y Tolomeli, "Italy," 88.
} 
armados de izquierda (los más conocidos fueron los Gruppi Armati Partigiani, o GAP, y las Brigadas Rojas), lo cual prolongó el recurso de la violencia armada durante toda la década del ' 70.13

Un sistema educativo en expansión, pero considerado por muchos como frustrante y anacrónico, un conflicto generacional librado sobre el terreno de la moral sexual y las formas cotidianas de uso del cuerpo, una cronología de acciones más extendida que en otros países, y niveles mayores de violencia en comparación con otros casos (como en Francia), fueron característicos del '68 italiano. Al mismo tiempo, un elemento particularmente específico del caso italiano fue la manera en que la protesta estudiantil pronto se asoció al activismo obrero. Pocos meses después de pasado el momento de máxima movilización en las universidades, estalló una oleada de huelgas acompañadas de una intensificación de la militancia gremial de base. Muchas de sus demandas, de hecho, se vinculaban con protestas sobre la forma de representación gremial, las características del proceso de trabajo, y la necesidad de mayor horizontalidad en la representación de los obreros. Con amplia participación y protagonismo de los obreros más jóvenes, el llamado "otoño caliente" del '69 prolongó el estado de movilización y activismo entre los militantes estudiantiles. Acciones conjuntas, y diversas formas de encuentro sellaron de manera más exitosa que en otros lados la confluencia entre estudiantes y obreros. De hecho, la oleada de agitación en Italia se prolongó durante varios años, y experimentó diversas formas de activismo y radicalización hasta mediados de la década de 1970.14

Finalmente, un aspecto también saliente del '68 italiano fue el hecho de que la movilización social encontró una cultura de izquierda en proceso de diversificación y renovación. Si bien esto se puede decir también de otros países, el caso italiano presenta rasgos propios. Italia contaba de hecho con un Partido Comunista (PCI) con una fuerte implantación política y cultural. Siendo la segunda fuerza política del país (luego de la gobernante Democracia Cristiana), el PCI había desarrollado desde su re-implantación en 1944 una estrategia de expansión cultural que le permitió insertarse en los sindicatos, entre los intelectuales, y a nivel local a través de sus clubes, sedes partidarias, centros culturales, organizaciones juveniles y de mujeres, y diarios y revistas propios. ${ }^{15}$ Hacia inicios de la década de 1960, y en parte como efecto de los episodios de 1956 (el informe Kruschev y la invasión a Hungría por parte de la URSS), el PCI había comenzado a relajar el control dogmático de su esfera cultural, a la par que había dejado de monopolizar la cultura de izquierda. Surgieron así nuevas iniciativas independientes e incluso hostiles a sus directivas. Una de las más notorias fue la aparición de una serie de revistas usualmente consideradas como parte de la "nueva izquierda" en Italia (Quaderni Rossi, Classe Operaia, Sinistra, Classe e Stato, y Quaderni Piacentini, entre otros). Si bien limitados en su tirada, y poco efectivos en cuanto a política organizativa, tanto estas revistas como diversos dirigentes y militantes al interior del PCI, fueron activos en diversificar el repertorio cultural de la izquierda. ${ }^{16}$ Surgieron así polémicas y discusiones en torno a la juventud y las nuevas generaciones; las características de la sociedad de masas en el capitalismo avanzando y las formas posibles de intervención crítica; o la apertura a teorías y corrientes del pensamiento ajenas de la raigambre del marxismo soviético, como la sociología crítica norteamericana, los líderes de los procesos de liberación del Tercer Mundo, la Escuela de Frankfurt, o el psicoanálisis.

\footnotetext{
13 En el período de 1969-1974, los grupos de extrema derecha fueron responsables de 63 muertes, siete veces más que los de izquierda. Debido a la propagacion de la violencia armada, el ciclo 1969-1980 se suele denominar "los años de plomo" en la historia italiana. Ver Isabelle Sommier, La violencia revolucionaria, Buenos Aires, Nueva Visión, 2009, pp. 56-59; Lumley, op. cit, 279-294; Ginsborg, op. cit, 358-366.

14 Ver Ginsborg, op. cit, 309-333, Lumley, op. cit, passim.

15 Para una historia del PCI durante la segunda posguerra, ver Stephen Gundle, Between Hollywood and Moscow: The Italian Communists and the Challenge of Mass Culture, 1943-1991, Durham, Duke University Press, 2000; y Ginsborg, op. cit, 82-85; 195209; 290-297; 305-308; y David Forgacs, L'industrializarazione della cultura utaliana (1880-2000), Bolonia, Il Mulino, 1992, pp. 233264 ..

16 Según Lumley, las revistas como Quaderni Piacentini o Classe Operaia editaban entre 4000 y 5000 copias respectivamente. De todas formas, considera que no hay que menospreciar la influencia de estas revistas entre activistas y militantes. Lumley, op cit, 38 .
} 
De esta forma, el '68 italiano encontró una cultura de izquierda con muchos recursos intelectuales para procesar los acontecimientos de ese momento. A esto contribuyó sin dudas que el PCI mantuvo una actitud abierta sobre las nuevas protestas, manteniendo una postura heterogénea que combinó simpatía, con cauta distancia y, en el caso de los dirigentes más adultos y conservadores, hostilidad. De hecho, en contraste con la experiencia francesa (en la que el '68 implicó un retroceso electoral y político importante para el PCF), en Italia el PCI no se vio debilitado por el auge de las protestas. ${ }^{17}$ De la misma manera, dentro de los autores y revistas de la nueva izquierda, los episodios desatados a partir de la movilización estudiantil fueron un aliciente para desplegar diversos tipos de miradas y análisis y buscar enriquecer las formas de intervención política y cultural. Muchos de los temas preponderantes dentro del movimiento estudiantil del '68, tales como la necesidad de superar la división tradicional entre trabajo intelectual y trabajo manual, la critica a estructuras políticas jerárquicas, o la necesidad de actualizar los clásicos del marxismo a las modalidades del capitalismo contemporáneo, eran un legado del mundo de revistas y autores de la nueva izquierda. La expansión universitaria y el estallido de las revueltas dotó de un público nuevo y movilizado a una cultura política formada previamente. De la misma manera, planteó interrogantes y desafíos teóricos a personas formadas en este legado, y que ahora encontraban una nueva realidad por desentrañar. Los autores reseñados más abajo son en cierta manera representativos de esta situación.

\section{Una revuelta anti-edípica en una sociedad post-edípica}

No debería sorprendernos que entre los tantos observadores y analistas de los acontecimientos del '68, se encuentre la periodista, novelista, y directora de cine Lorenza Mazzetti. Desde principios de la década, Mazzetti estaba a cargo de la columna de consejos sentimentales y personales del semanario comunista Vie Nuove, que era una publicación dirigida a un público amplio de izquierda, y que reproducía el formato de las revistas más masivas y comerciales (mezclando temas de actualidad con tapas mostrando modelos y actrices, e información variada sobre temas de vida cotidiana y espectáculos). ${ }^{18}$ La columna de Mazzetti se adaptaba al perfil de la revista, incluyendo desde consejos sobre lecturas, películas y cuestiones intelectuales, a respuestas a lectores que le hacían llegar sus problemas personales, de pareja, de relación con los hijos, etc. A medida que Mazzetti se afianzó en su columna, fue expandiendo el uso de nociones psicoanalíticas, lo cual combinaba con cuestiones de género, además de referencias ineludibles a la bibliografía marxista.

Desde mucho antes del estallido de las protestas en las universidades, Mazzetti había dedicado una buena parte de sus columnas a tratar el tema de la juventud contemporánea, analizando en qué medida las nuevas expresiones culturales y artísticas eran escapistas y superficiales, o contenían elementos de genuina rebelión y protesta. En algunas ocasiones, incluso criticaba a los jóvenes militantes del PCI por ser demasiado cerrados a las nuevas modas o tendencias de la cultura juvenil. ${ }^{19}$ Precisamente por esto, sus posicionamientos sobre la movilización estudiantil no tardaron en aparecer. De hecho, hacia diciembre de 1967, en el momento de auge de la protesta universitaria, publicó la carta que una chica de 18 años llamada Paola, estudiante de filosofía, le había escrito para comentarle su compromiso con la protesta estudiantil. La carta exhibía el rechazo de Paola a su familia aburguesada y convencional, su desprecio por su madre y su limitado rol de ama de casa, y describía la vorágine de lecturas en las que se sumergía de manera caótica y desordenada ("Gramsci, Marx, Lenin, Guevara,

\footnotetext{
17 Tal cual observa Lumley, si bien hubo una línea muy hostil a las revueltas juveniles, la línea oficial impulsada por Luigi Longo fue de apoyo a las movilizaciones estudiantiles. Ver Lumley, op cit, 73-74, 76. Sobre la actitud hostil del PCF ante la protesta estudiantil en Francia, ver Eley, op cit, 341-365; y para una panoramica de la cultura de izquierda y el '68, ver Sasoon, op cit, pp. 383-406. Sobre el PCI italiano en esta época, ver Ginsborg, op. cit, 305-309, y Gundle, op. cit, 106-137.

18 Para Vie Nuove ver Stephen Gundle, Between Hollywood and Moscow: The Italian Comunists and the Challenge of Mass Culture, $1943-$ 1991, Durham, Duke University Press, 2000, 38-39, 67-69, 93-96.

${ }^{19}$ Lorenza Mazzetti, "Il grande rifiuto dei giovani,” Vie Nuove, n 20, 18 de Mayo de 1967, 41.
} 
Debray, Castro, Ginsberg, Kerouac, Miller, Lorca, Sartre, Russell”). Su carta de presentación no dejaba de lado su combativo inconformismo,

soy siempre la primera, en las huelgas y en las marchas de protesta, a gritarle "fascistas" a los tutores del orden público [...] Odio los paternalismos, las cadenas doradas de la esclavitud del "bienestar" [...] Miro en torno a mí y ¿qué veo? Gente beata, aburrida, robots, bulones de una cadena de montaje, para quienes todo va bien, incluso si los EEUU agreden Vietnam o a América Latina... ${ }^{20}$

Los rasgos de Paola parecen tan estereotipados que podríamos preguntarnos si realmente existió, o si era una estrategia de Mazzetti para comenzar una conversación sobre la protesta estudiantil que se expandía por toda Italia. Lo que sí está claro, de todas formas, es que su actitud estuvo lejos de ser condescendiente o halagadora de su comprometida corresponsal, y es de hecho reveladora de la distancia entre una intelectual en sus 40 años ligada al PCI como Mazzetti, y las nuevas formas de protesta estudiantil. La respuesta de Mazzetti a la carta, de hecho, empieza de manera devastadora: "me parece que la chica que me escribe está en un grave estado neurótico." Y luego se expande en una explicación con el característico tono psicoanalítico muy común en su columna. Según su interpretación, las chicas como Paola se rebelaban genuinamente contra los roles de femineidad limitantes que recibían de sus madres, pero caían en el exceso de adoptar modelos masculinos que ocluían totalmente su dimensión femenina, y las dejaba a disponibilidad de proyectos políticos que las ponían en riesgo físico o les impedía desarrollar otras dimensiones de sus vidas. Mazzetti no dejaba de referir a cómo "la identificación con su ídolo Che Guevara" era parte de esta neurosis, o incluso calificaba su extremismo como "una etapa de latente homosexualidad" por adoptar roles tan propiamente masculinos. Según Mazzetti, al hacer esto se constituía como el inverso de la limitación de la madre: si ésta renunciaba a lo público para limitarse a lo doméstico, Paola se abandonaba totalmente a lo político. O como lo decía en otros términos, las chicas extremistas "no comprenden el sentido del nuevo rol de la mujer, y confunden la evolución ineluctable de la mujer con la negación de la propia femineidad y la identificación con la masculinidad."21

No tardaron en aparecer reacciones al análisis de Mazzetti. En tono a veces amigable, y otras más agresivo, distintos lectores le criticaron su identificación del extremismo como neurosis, o el ver el tipo de acciones de Paola como algo no femenino. ${ }^{22}$ Esto llevó a Mazzetti a profundizar su análisis. Para ella, el tipo de acciones espectaculares y vistosas en las que incurrían los estudiantes, su política de "todo o nada" y de enfrentamiento heroico con un poder exterior, eran todos síntomas de que no se habían resuelto debidamente conflictos interiores. O peor aún, "coartadas" para no enfrentarse con los propios aspectos inconscientes. En esto Mazzetti era más que clara: los jóvenes en rebelión estaban todavía acechados por la culpa de sus conflictos inconscientes. Por un lado, rechazaban la sociedad de consumo y el poder represivo, pero por el otro aún dependían y estaban condicionados por esa sociedad en la que se habían formado, y cuyos valores habían internalizado a través de sus figuras paternas. Forjar modelos heroicos y épicos complicaba más las cosas porque aumentaba la discrepancia entre lo que eran y lo que pretendían ser. Como decía Mazzetti comprensiva, esto los podía llevar a que "terminen decepcionándose a sí mismos, y en la autodestrucción inconsciente para castigarse por no haber sabido ser como hubieran querido." 23 Según ella, el destino de no hacer las cuentas con sus conflictos interiores se pagaba con un sentido de culpa incrementada, y la búsqueda neurótica de castigo y autodestrucción.

20 Mazzetti, "Estremismi d'una ragazza d'oggi," Vie Nuove, 49, 7 de Diciembre de 1967.

${ }^{21}$ Idem

22 Mazzetti, "L'alibi del tutto o niente," Vie Nuove n 1, 4 de Enero de 1968; "Coscienza e rivoluzione”, Vie Nuove, n 3, 18 de Enero de 1968; "La cinese," Vie Nuove, n 7, 16 de Febrero de 1968.

${ }^{23}$ Mazzetti, "L'alibi del tutto o niente." 
En su análisis, Mazzetti dejaba bien en claro que la tendencia a la acción dramática, espectacular y exagerada en que incurrían los estudiantes tenía todas las características de un síntoma neurótico. Y que por otra parte reproducían rasgos más comunes de la sociedad que decían criticar, es decir, aquella que valoraba la espectacularidad a toda costa, y "solo aquello que hace acudir a los fotógrafos." 24 Pero como afirmaba insistentemente, "la lucha por el Vietnam" es una lucha también "dentro de nosotros." Su postura resaltaba la necesidad y el valor de una actitud más sobriamente introspectiva, que consideraba condición indispensable de una acción genuinamente revolucionaria,

tan poca importancia se le da a la acción no vistosa o simplemente interior de la formación de sí (como si esta actividad de toma de consciencia, de estudio y de formación interior no fuese la premisa de cualquier revolución), que se termina por atribuir un valor de salvación y un valor revolucionario solo a esto que es épico y heroico (y que a veces es imposible realizar dadas las circunstancias) y con transformar esta imposibilidad temporal (...) en una coartada para rechazar hacer aquel poco, aquella acción modesta pero profunda, de revolución en sí mismos y en los propios comportamientos. ${ }^{25}$

Mazzetti escribía estas líneas tan críticas y (en el caso de su respuesta a Paola) normativas en el momento de mayor movilización y prestigio del movimiento estudiantil, mucho antes de marzo del '68 y su momento de tensión y reflujo. Paradójicamente, luego de la "batalla de Valle Giulia," cuando los estudiantes fueron más criticados y quedaron más aislados, su posición se volvió más comprensiva, e incluso entusiasta. De hecho, comenzó a hacer propios muchos de sus proyectos y percepciones. Por un lado, le atribuyó una legitimidad fundamental a la rebelión estudiantil como parte de un "gran rechazo" a ocupar la posición privilegiada que el sistema educativo les reservaba. Por otro lado, tomó una posición más clara con respecto a la violencia. Muy influenciada por visiones del cura católico José María González Ruiz, se volvió más proclive a denunciar la "violencia desde arriba" o la "violencia del sistema" que producía desigualdad, exclusión, y condicionamientos de todo tipo, y que no dejaba lugar para una pasividad indiferente. ${ }^{26}$ Finalmente, desarrolló con más precisión sus ideas sobre del rol de la culpa y la neurosis en la sociedad capitalista avanzada. Nada de esto, sin embargo, cambió su postura de fondo: la revolución genuina implicaba una liberación de los condicionamientos psicológicos y los conflictos inconscientes que aferraban al individuo a una sociedad explotadora. O como lo afirmaba en sus propios términos: "la acción revolucionara no puede sino pasar a través de la experiencia del inconsciente, a través de la recuperación de lo reprimido, a través de la destrucción de la 'falsa conciencia."' 27

El punto de arranque de la postura más comprensiva de Mazzetti era que los estudiantes estaban iniciando un proceso de contestación global más que genuino y revolucionario. Se trataba de rechazar el lugar de técnicos y expertos privilegiados reservado para ellos por la sociedad capitalista avanzada. En la sociedad de consumo del capitalismo desarrollado (o "neocapitalismo," según la expresión de Mazzetti), la cohesión social ya no provenía de la amenaza o la represión abierta, sino de formas más sutiles de creación de consenso y conformismo ligadas a la publicidad, el sistema educativo, el consumo de masas y otras técnicas de control social. Habiendo experimentado estas técnicas en sí mismos, como estudiantes universitarios, los jóvenes rebeldes rechazaban el transformarse ellos mismos en profesionales de las técnicas de manipulación de masa y de reproducción de las desigualdades del sistema. Era por eso que su lucha no consistía en una petición de demandas específicas, derechos, o privilegios, ni tampoco en una canasta de reformas educativas (que solo

\footnotetext{
24 Idem.

25 Idem.

26 Mazzetti, "Contestazione globale", Vie Nuove, n 11, 14 de Marzo de 1968; "Violenza obligatoria," Vie Nuove, n 12, 21 de Marzo de 1968

27 Mazzetti, "Psicoterapia e revoluzione," Vie Nuove, n 26, 27 de Junio de 1968, p. 29. Se trata de la introducción a un dossier sobre "Neurosis y sociedad" preparado por Mazzetti para la revista.
} 
perfeccionaría la efectividad de su manipulación). Por el contrario, la actitud de los estudiantes era parte de una "revolución psicológica" contra "el adormecimiento de la consciencia y los métodos infinitos y siempre nuevos de condicionamiento camuflados y ocultos." 28 Expuesto en estos términos, el movimiento presentaba rasgos atractivos para Mazzetti, al ser una denuncia profunda de la sociedad de consumo, además de una contienda que se disputaba en el terreno de la psiquis.

En muchos aspectos, Mazzetti mantenía las premisas de su análisis anterior. El rechazo a volverse la parte privilegiada de un sistema de integración condicionante partía de un sentimiento claro: la culpa. Era por el complejo de culpa por ser cómplices de un sistema de explotación que los estudiantes iniciaban su revuelta. Pero de a poco Mazzetti fue precisando mejor algunas ideas en torno a la culpa y la neurosis. Su concepción de que en el capitalismo avanzado el poder ya no funcionaba de manera represiva, ni a partir de la sacralización y santificación de la autoridad, se traducía en el plano psicológico en que el súper-yo no aparecía bajo el prototipo del padre represivo y autoritario. Por el contrario, ahora esta instancia aparecía con la "cara alegre" del publicista que ofrece nuevos bienes y fomenta actitudes de licencia, hedonismo, e individualismo. Este poder, a su vez, era mucho más invasivo y absorbente que el modelo anterior, y envolvía al individuo en una "falsa conciencia" acerca de sí mismo y sus deseos, a la vez que lo disociaba y escindía de toda una dimensión afectiva no funcionalizable por el sistema. Es por esto que la forma más acabada del capitalismo no era la neurosis (que en definitiva implicaba un conflicto), sino la esquizofrenia, en la cual se perdía todo tipo de contacto con lo reprimido. ${ }^{29}$

En este análisis, la culpa se volvía una forma de resistencia de una dimensión de los estudiantes que se negaba a ser integrada al sistema. Esto no quería decir, sin embargo, que la culpa y la neurosis por sí mismas fueran liberadoras. Pero lo que estaba claro para Mazzetti era que el malestar e incluso la desesperación que se transmitían a partir de la neurosis eran un momento en un proceso de toma de conciencia que debía terminar en la práctica revolucionaria colectiva. Esto le permitía sentenciar tajantemente que "la neurosis de los individuos en una sociedad opresiva no es solo un evento clínico, es un evento político,"

Cuando la realidad social nos aparece insoportable, cuando vemos a los otros como extraños, el rechazo de la sociedad y de los otros lleva al individuo neurótico al aislamiento, a la desesperación, al extrañamiento [estraneità] y finalmente al convencimiento de ser enfermo y anormal en una sociedad sana y normal. Este estado de ánimo es un "momento" del viaje para liberarse de las incrustaciones de la "falsa conciencia" en la búsqueda del sí mismo, o de esa parte del sí mismo que trasciende el yo individual, para fundirse con el "yo" colectivo, el "nosotros" revolucionario.30

Es precisamente en torno al tratamiento de la culpa como momento de un proceso de conversión revolucionaria, que Mazzetti desarrollaba una temática clásica de los textos freudianos, aunque re-leída en clave de uno de sus nuevos ídolos culturales: Herbert Marcuse. En la apropiación del psicoanálisis elaborada en su libro Eros y civilización, Marcuse había desarrollado una reinterpretación del mito freudiano de la horda primitiva y el parricidio originario. Según esta idea de Freud, el origen de la civilización y de las primeras instituciones sociales se explica por un episodio hipotético de enfrentamiento entre un padre que monopolizaba el poder y la autoridad, y sus hijos destituidos. Como fruto de este conflicto, los hijos matan al padre autoritario, pero debido a la presión de la culpa por el hecho cometido, reintroducen la adoración al poder patriarcal, reproduciendo de manera más poderosa la dominación que querían derribar. ${ }^{31}$ La religión y las primeras instituciones legales son derivados de esta adoración. Este mismo proceso era, para Marcuse, el destino trágico de todas las revoluciones:

28 Mazzetti, "Rivoluzione psicologica," Vie Nuove, n 13, 28 de Marzo de 1968.

${ }_{29}$ Mazzetti, "É fuori di se," Vie Nuove, n 9, 1 de Marzo de 1968.

30 Mazzetti, "La responsabilità collettiva," Vie Nuove, n 23, 6 de Junio de 1968.

31 Ver Sigmund Freud, “Totem y tabú: algunas concordancias en la vida anímica de los salvajes y los neuróticos,” Sigmund Freud, Obras completas, vol. 13, Buenos Aires, Amorrortu, 2012, 142-148. 
incrementar las formas de dominio y control social sobre las pulsiones de los individuos. Leído en esta clave, Marcuse se permitía también una re-interpretación del texto freudiano. La culpa que paralizaba el accionar revolucionario no provenía solo de la ambivalencia hacia el padre (que de hecho quedaba expiada a través de diversos rituales totémicos), sino de la intuición de haber traicionado las promesas emancipatorias que motivan las acciones revolucionarias. Solo cuando se retome el contacto con esos deseos utópicos traicionados, se podrá encauzar una revolución verdaderamente liberadora que permita una existencia social sin culpa ni angustia. ${ }^{32}$

A lo largo de los meses en que escribió sobre la revuelta estudiantil, la influencia y la adoración de Marcuse por parte de Mazzetti crecieron exponencialmente. Siendo prácticamente innombrado en su columna en los años previos, hacia 1968 pasó a celebrarlo como el profeta del movimiento de los estudiantes. ${ }^{33}$ Muchas de las nociones de Mazzetti, de hecho, eran elaboraciones de ideas marcusianas, como la idea del nuevo estatus del súper-yo en el capitalismo avanzado, o la necesidad de movilizar el psicoanálisis como forma de emancipación de las limitaciones de la consciencia alienada. Muy probablemente, Marcuse fue un vínculo más que conducente de sus expectativas y sus esperanzas sobre el movimiento estudiantil (y que diferenciaba a Mazzetti de colegas cercanos como Pier Paolo Pasolini, que tenían visiones más negativas de los estudiantes). ${ }^{34}$ Pero de manera todavía más crucial, las ideas que tomaba de Marcuse le daban claves de análisis para acompañar la revuelta estudiantil desde una perspectiva crítica. Esto fue el caso de cómo elaboró las ideas de Marcuse en torno a la "revuelta edípica” y sus peligros.

Siguiendo a Marcuse, Mazzetti observó una gran contradicción de los estudiantes. Por un lado, enmarcaban sus acciones y su voluntad en contra de sus familias, o de figuras paternales de remplazo, como los profesores, la clase dirigente, los partidos tradicionales, o la policía. Al hacer esto, seguían pensando el poder en términos tradicionales, es decir, tomando la figura paterna como modelo exclusivo de autoridad social. No se daban cuenta, según Mazzetti, que en la sociedad capitalista avanzada el poder ya no funcionaba de esa manera, puesto que ahora las reglas y pautas de conducta eran impuestas mediantes las técnicas de manipulación de la sociedad de masas. O sea que el gran problema de los estudiantes es que se rebelaban contra una "sociedad post-edípica," pero en términos de la anacrónica "revuelta edípica." Mazzetti temía, por otro lado, que si insistían por esta vía iban a seguir el destino de todas las revoluciones anteriores: se iban a poner en el lugar del padre, reproduciendo su poder patriarcal de manera ampliada. Este balance la hacía insistir en su prédica de más largo aliento: lo importante no era dirigirse a poderes exteriores (si bien esto era un momento ineludible de la acción revolucionaria) sino a las formas en que éstos eran internalizados mediante el súper-yo. El poder del sistema no operaba mediante sus agentes visibles externos, sino a través de sus mecanismos psicológicos,

Gracias a Freud, podemos saber hoy que no son solo las autoridades externas y visibles que debemos combatir, sino también su introyección en nuestra psiche (...) puesto que si no somos conscientes de su presencia invisible en nuestro inconsciente como súper-yo, no seremos nunca libres, sino que, apoderados por una angustia que no sabemos de dónde viene, nos apresuraremos mecánicamente para encontrar alivio a restaurar externamente al padre-rey y sus leyes, el sistema-padre. ${ }^{35}$

\footnotetext{
32 Herbert Marcuse, Eros and Civilization, Nueva York:, Vintage, 1955, 54-68.

33 Mazzetti, "L'incoronazione dei figli," n 34, 22 de Agosto de 1968. Sobre la influencia de Marcuse entre los estudiantes y activistas del '68 ver Lumley, op. cit, 121-122. El libro El hombre unidimensional, de Marcuse, fue traducido en 1967 y vendió 150.000 copias en un año.

34 Sobre la reacción negativa de Pasolini sobre los estudiantes del '68, ver Ginsborg, op. cit, 307-308. Mazzetti discutió abiertamente con Pasolini (a quien admiraba), en Mazzetti, "Il PCI ai giovani," Vie Nuove, n 25, Junio de 1968.

35 Mazzetti, "L’incoronazione."
} 
Si Freud daba los términos de análisis, Marcuse le permitía vislumbrar una posibilidad optimista. Si el origen de la culpa estaba en la traición al impulso que había llevado a la rebelión, lo que debían hacer los estudiantes era rescatar los deseos de hermandad, solidaridad, e igualdad. Algo que experimentaban tanto en las formas de comunidad entre estudiantes, como en los puentes que trazaban con sus otros "hermanos": los obreros. Ponerse en contacto con esta dimensión afectiva era lo que iba a permitirles recomponerse como individuos totales en el medio de la esquizofrénica sociedad capitalista. Al desarrollar este razonamiento, el uso del psicoanálisis por parte de Mazzetti le permitía también criticar algunas actitudes y prácticas del movimiento estudiantil, pero sin incurrir en una posición abiertamente conservadora u hostil. Su postura de que la verdadera revolución pasaba por una liberación interior que habilitara una acción colectiva menos espectacular, le permitía proclamarse como solidaria con los fines y objetivos de los estudiantes, pero sin avalar sus posturas más extremas, o aquellas prácticas y transformaciones de roles que para Mazzetti aparecían como demasiado rupturistas. En esta clave, su versión comprometida y marcusiana del psicoanálisis resultaba idónea para tomar distancia del movimiento estudiantil, pero amparándose en uno de sus propios líderes culturales.

\section{El deseo disidente}

Como mencionamos más arriba, el segundo autor aquí estudiado difiere significativamente del primero. A diferencia de Mazzetti, Elvio Fachinelli (1928-1989) era un médico especializado en psiquiatría, que había iniciado su análisis en 1962 con uno de los pioneros del psicoanálisis italiano, Cesare Musatti, para pronto volverse miembro de la Società Psicoanalítica Italiana [SP]. Paralelamente, se destacó en el mundo editorial como traductor al italiano de textos centrales de Freud (como La Interpretación de los sueños), o como miembro de la revista Il Corpo (1965-1968). Desde 1967 también se volvió colaborador regular de la revista Quaderni Piacentini, en donde publicó una serie de artículos sobre psicoanálisis y los movimientos del '68. Pero esto no evitó que poco después fundara su propia revista y editorial, L’Érba Voglio (1971-1977) que es considerada como una de las expresiones más representativas de la contracultura del pos-68 italiano. ${ }^{36}$

El carácter multifacético de Fachinelli se puede detectar en los múltiples registros en los que se movía (el marxismo, el existencialismo, el psicoanálisis, el estructuralismo), así como en la dificultad para clasificarlo o rotularlo. Por un lado, fue un profundo lector de Marx, pero crítico de actitudes y premisas de la izquierda italiana. Análogamente, dentro del mundo del psicoanálisis su posición fue también a contrapelo de diferentes tendencias. Fue uno de los primeros lectores de Jacques Lacan en Italia (reconocido por el propio Lacan), y formó parte del grupo Plataforma, que organizó un contracongreso en julio de 1969 contra la International Psychoanalytical Association [IPA] (la organización internacional ortodoxa de psicoanálisis). Pero al mismo tiempo se negó a abandonar la sociedad psicoanalítica oficial de Italia, o a encabezar un grupo disidente junto a los lacanianos italianos, anticipando que hacerlo implicaría reproducir lo mismo que se criticaba. ${ }^{37} \mathrm{En}$ sus distintas intervenciones y en su itinerario se advierte el perfil de alguien que prefiere mantenerse como marginal al interior de las instituciones, y como un francotirador que escribe artículos en donde se vincula lo coyuntural con lo teórico y lo clínico, pero sin sistematizar ni formalizar sus términos o categorías de análisis.

Como con Mazzetti, no deberíamos sorprendernos que Fachinelli dedicara gran parte de sus esfuerzos y atención a las revueltas estudiantiles. Ya antes del momento álgido de la movilización, Fachinelli había demostrado su capacidad para usar el psicoanálisis como una crítica a las formas de exclusión del sistema educativo. Esto se transparenta en el análisis que había dedicado en Quaderni

\footnotetext{
36 Sobre el itinerario de Fachinelli, ver Marco Conci y Francesco Marchioro (eds), Elvio Fachinelli: Intorno al '68. Una antologia di testi, Bolsena (VT), Massari Editore, 1998, 7-20. Sobre la revista Quaderni Piacentini y L'Erba Voglio, ver Lumley, op. cit, 34-38, 297.

${ }^{37}$ Sobre el itinerario de Fachinelli, ver Marco Conci y Francesco Marchioro, “Introduzione,” Conci y Marchiori, op. cit, 7-52.
} 
Piacentini al libro de Lorenzo Milani, Cartas a una maestra normal. Tras citar largos fragmentos del texto en donde se denunciaba cómo la escuela italiana relegaba a los chicos más pobres, Fachinelli observaba que el libro producía una sensación extraña en el lector, porque en verdad demostraba algo que los lectores ya sabían pero que hacían un esfuerzo por no recordar: la manera en que a lo largo de sus estudios veían perderse y alejarse de la escuela a toda una categoría de compañeros que eran considerados no aptos para las exigencias escolares. O como afirmaba explícitamente, "lo olvidamos continuamente. La sorpresa, junto al malestar, nace del hecho de que ahora vemos una cosa que sabíamos, y que habíamos olvidado, alejado de nosotros." 38

En el curso de sus estudios, sostenía Fachinelli, el alumno de clase media progresa en un sistema que privilegia los saberes y habilidades de su sector social. Y aquellos que son externos a estos privilegios quedan en el camino, y son "olvidados," reprimidos en el sentido social y psicoanalítico. Lo que hacía el libro de Milani, según Fachinelli, es enfrentar al lector (que seguramente será un graduado universitario o de la secundaria) con lo reprimido, al recordarle los casos de quienes no han seguido dentro del sistema escolar. Y además, poner en evidencia la asimetría: mientras que para los "exitosos" el paso escolar de los reprobados es un detalle olvidado, muy probablemente para quienes han tenido un paso frustrado por la escuela, el olvido no ha ocurrido: "ellos no nos han olvidado, no llegan a olvidarnos." ${ }^{39}$ De allí la fórmula que se permite Fachinelli: "mi represión individual de lo social es paralela a la represión social de los individuos. Y esto que es reprimido (...) permanece, está siempre despierto, me deforma desde adentro, incluso si lo ignoro." 40

Esta perspectiva le permitía no quedarse solamente en la denuncia de la exclusión. Por el contrario, lo que también le interesaba a Fachinelli era mostrar la manera en que la exclusión estaba activa en el integrado. Como sostenía, el alumno adaptado, el hijo de la familia de clase media urbana que atraviesa exitosamente sus estudios, "paga caro su privilegio." 41 Su validación social consiste en ganar aceptación dentro de un esquema rígido en donde ingresan solo los que tienen rasgos similares, en general acartonados y "académicos." Pero dado que ese proceso de selección es reprimido e invisibilizado, la cultura, la educación, aparece como algo mistificado y trascendental, y no como el resultado de relaciones sociales desiguales. El privilegiado es quien se ha despersonalizado y asimilado a un conjunto de valores, instituciones y formas de prestigio cuyo origen social se oculta, lo cual hace a su poder todavía más opresivo. De allí que para Fachinelli, "lo que se muestra en el libro es la fragilidad de nuestra identidad personal; esto que nos asusta, y de lo cual se nos amenaza, es en el fondo la pérdida de esta identidad." ${ }_{2}$ Y esto básicamente porque con el libro de Milani, según Fachinelli, no podemos no ver "el modo en que hemos sido formados como el modo de nuestra deformación." 43

Las reflexiones de Fachinelli sobre el libro de Milani formaban parte de una sección de Quaderni Piacentini especialmente dedicadas a discutir ese texto, cuyo impacto durante 1967 fue enorme, incluso antes de los episodios más llamativos del movimiento estudiantil. Pero cuando finalmente la revuelta tomó las dimensiones dramáticas que pusieron a las universidades en el centro de la escena política, el interés y las iniciativas de Fachinelli no se hicieron esperar. Esto se transparenta en dos textos de análisis del movimiento estudiantil, publicados en Quaderni Piacentini en el lapso de pocos meses: "El deseo disidente," y “¿Grupo cerrado o grupo abierto?” En el primer caso, escrito en el invierno del '67-'68, Fachinelli observaba lo sorprendente de la fugacidad y la intensidad de las protestas estudiantiles. Comenzaban con una serie de demandas encabezadas por líderes específicos, que luego eran desplazadas por otras peticiones, que a su vez eran reemplazados por nuevos programas, siempre en busca de una constante renovación y una renuncia a la conciliación o a la negociación en torno a

\footnotetext{
38 Fachinelli, "Intervento sul libro di Don Milani," Conci y Marchioro (eds), op. cit, 70.

39 Ibid, 71

40 Idem.

41 Idem.

42 Ibid, 71-72.

43 Idem
} 
puntos concretos. Y todo esto acompañado de un grado de intensidad y movilización notables. Como si la protesta replicara la rotación espectacular de la sociedad de consumo y sus modas cambiantes. Era precisamente esta relación entre la protesta y el capitalismo industrial desarrollado lo que le parecía central a Fachinelli.

Según Fachinelli, en la sociedad contemporánea los estudiantes eran convocados a ejercitar profesiones jerarquizadas y redituables, pero dentro de esquemas rígidos y normas fijas que constreñían su iniciativa y creatividad. La fórmula que se les ofrecía era: "te libero de la necesidad, pero te hago renunciar al deseo." $44 \mathrm{El}$ centro de la protesta había que entenderlo entonces como un rechazo de ese pacto. Lo que los estudiantes buscaban con sus agrupamientos intensos y sus formas dramáticas y cambiantes de acción y cohesión era precisamente eso: el "estado de deseo". De allí el estupor de rectores, policías, y políticos frente a la protesta. Todos se preguntaban: ¿qué quieren los estudiantes?, como si eso pudiera encontrarse en un listado de reivindicaciones sobre la cual poder negociar, tal cual ocurriría con un grupo corporativo tradicional. ${ }^{45}$ Pero esa lógica no aplicaba a lo que Fachinelli llamaba un "grupo de deseo." A diferencia de grupos que siguen una lógica de la necesidad a través de demandas concretas, el "grupo de deseo" busca su propia supervivencia, y su deseo más concreto es básicamente ese: el deseo mismo. Si logra ser arrinconado en torno a una demanda, y esa demanda es satisfecha, entonces el grupo logra su objetivo, la movilización se disuelve, y el deseo muere. Y a lo que más le teme el grupo de deseo es precisamente a eso... a que su deseo se extinga en una sociedad en la cual ya no van a tener otros espacios para actualizarlo.

Como a lo largo de todos sus escritos, el texto de Fachinelli pegaba en varios frentes. Por un lado, y al igual que Mazzetti, introducía temáticas sociales desde las cuales re-pensar el psicoanálisis. En ese sentido, compartía la misma influencia de los pensadores de la Escuela de Frankfurt, sobre todo en la temática de las transformaciones en torno al rol paterno. En la sociedad capitalista avanzada, acordaba Fachinelli, el poder funcionaba en torno a sistemas de integración y no a una autoridad patriarcal prohibitiva. De allí que el rechazo de los estudiantes a figuras de autoridad no había que interpretarlo como un desplazamiento del conflicto edípico. Echando mano a nociones cercanas a la psicoanalista Melanie Klein, Fachinelli consideraba que el rechazo de los estudiantes a la integración y la adaptación era el resultado de que el capitalismo avanzado se les aparecía como una madre sobreprotectora: calmaba sus necesidades, pero los despersonalizaba. Los enemigos del movimiento entonces no eran desplazamientos paternales, sino personificaciones de la dimensión del sistema que los destruía como seres deseantes. ${ }^{46} \mathrm{Al}$ mismo tiempo, esta evaluación no dejaba intocado al psicoanálisis. Fachinelli consideraba que muchas veces los psicoanalistas se dejaban llevar por nociones rígidas del principio de realidad, ante lo cual veían la protesta como una huida de la realidad, sin entender la realidad social de la adaptación despersonalizante en el capitalismo avanzado. ${ }^{47}$ Finalmente, no dejaba de hacer una crítica a la izquierda, que se manejaba con criterios de la lógica de la necesidad, menospreciando, por no saber entenderlos, a los grupos que se rigen por una lógica del deseo.48

Como Mazzetti, Fachinelli escribía desde una posición que alternaba el rechazo y la condescendencia hacia el movimiento estudiantil. El distanciamiento crítico, de hecho, se deja ver en el texto que es fruto de una experiencia de involucramiento directo con los estudiantes. Para el segundo semestre del año académico 1967-1968, los estudiantes de Sociología de la Universidad de Trento propusieron crear un "contra-curso" sobre "Psicoanálisis y sociedad represiva" (que fue el embrión de lo que luego se transformó en el primer curso estable de psicoanálisis en una universidad italiana). ${ }^{49}$

\footnotetext{
44 Fachinelli, "Il desiderio dissidente," Conci y Marchioro, op cit, 79.

45 Ibid, 80-81.

46 Ibid, 82-83.

47 Idem.

48 Ibid, 80.

49 La carrera de Sociologia de la Universidad de Trento, de hecho, se había creado como resultado de una movilizacion de estudiantes en 1966. Los "contracursos," su vez, fueron una modalidad de protesta muy expandida en todas las universidades durante esos años. Ver Kurz y Tolomelli, op. cit, 88-90.
} 
Fachinelli quedó a cargo del curso, y pronto les sugirió a los alumnos que en lugar de dictar lecciones a la manera tradicional, sería mejor transformar la clase en una sesión de psicoanálisis grupal. De esa experiencia surgió su artículo “¿Grupo cerrado o grupo abierto?” En el mismo, Fachinelli reproducía las intervenciones de las primeras semanas para mostrar las tendencias que existían dentro del grupo hacia el sectarismo y la búsqueda de cohesión identificando enemigos internos o externos que amenazaban la pureza y la salvación del grupo. Fachinelli llamó a este fenómeno "proceso de sectarización," y lo oponía a lo que él llamaba "proceso de agrupamiento [accomunamento]." En este último caso, que se había esbozado en la experiencia de Trento pero sin mayores consecuencias, la actitud consistía en buscar elementos comunes con los grupos o personas "externos" que refuercen los objetivos del grupo. A su vez, ambas situaciones producían liderazgos muy diversos: el posesivo y divisivo cuando predominaba la primera actitud, y que contrastaba con el más laxo y horizontal del segundo caso. Si bien Fachinelli reconocía que sus observaciones se basaban en un caso muy específico, su texto dejaba entrever que la lógica hacia el sectarismo era predominante dentro del movimiento estudiantil, y un elemento no menor de los "grupos de deseo" que había analizado en su artículo anterior. 50

Su distanciamiento con respecto a algunos aspectos del movimiento estudiantil no impedía que compartiera muchas iniciativas surgidas de las asambleas, el espíritu, y el estado de ánimo general de esos meses. Esto se ve más claramente en su participación en la experiencia de un jardín de infantes "anti-autoritario y auto-gestionado" montado por un grupo de estudiantes en la ciudad de Milán. El proyecto había surgido de un contra-curso sobre pedagogía en la Facultad de Filosofía y Letras de la Universidad de Milan durante el primer semestre del año académico 1968-1969. Siendo convocado como consultor, Fachinelli se plegó a la experiencia. Gran parte de sus esfuerzos organizativos y de muchos de sus artículos de esos meses estaban en relación con esa propuesta, que de hecho fue el origen del grupo L'Erba Voglio, que dio luego forma a la revista y a la editorial con el mismo nombre. ${ }^{51}$ Pero más allá de las alternativas de sus intervenciones, el proyecto sintetizaba la principal preocupación de Fachinelli durante esos meses, y el aspecto que más lo acercaba a la movilización: la búsqueda por pensar formas institucionales, pedagógicas y sociales novedosas y espontáneas que rompan con las actitudes burocráticas y autoritarias que encorsetaban saberes y prácticas.

Fue desde ese ángulo que se empezó a evidenciar su situación de crítica e incomodidad con las instituciones oficiales del psicoanálisis. Uno de los episodios fundamentales de estos meses, de hecho, fue el "contra-congreso" que un conjunto de psicoanalistas jóvenes organizó en Roma, en julio de 1969, para protestar contra las asociaciones psicoanalíticas oficiales. Durante esos días, tuvo lugar en el Hotel Hilton de Roma el congreso regular de la IPA, que por primera vez en su historia se reunía en Italia. El evento marcaba el ingreso de Italia al club de naciones del psicoanálisis (dado que durante mucho tiempo se la consideró como un país marginal o reacio al mismo). Pero más concretamente, también implicaba que la SPI se volvía finalmente reconocida oficialmente por la IPA, lo cual iba a significar un control más directo y estricto de los estándares de formación. ${ }^{52}$ Esta oficialización del psicoanálisis no fue bien recibida por algunos grupos de psicoanalistas, o candidatos a serlo, que organizaron una sesión alternativa en una cantina cercana, queriendo así contrastar con el espíritu más aburguesado y corporativo de la IPA. ${ }^{53}$ Sus peticiones tenían que ver con la rigidez en la formación, la falta de pluralismo teórico, y la demanda de mayor compromiso político y social por parte de los psicoanalistas. El evento fue exitoso en términos de repercusión, y tuvo su cobertura en diarios

50 Fachinelli, “Gruppo chiuso o gruppo aperto?” en Conci y Marchioro, op cit, 84-114.

${ }^{51}$ Los resultados y debates en torno al jardin auto-gestionado fueron publicados en forma de libro, luego de un congreso sobre el tema: Elvio Fachinelli, Luisa Muraro Valani, y Giuseppe Sartori (eds), L'erba voglio: Pratica no autoritaria nella scuola, Turín, Einaudi, 1971.

52 Ver la explicación sobre este punto ver Michel David, "La psychanalyse en Italie," Roland Jaccard (ed), Histoire de la psychanalyse, vol 2, Paris, Hachette, 1982, 324; 334-335.

53 Como dijo uno de los organizadores, "nos reunimos sin aire acondicionado, pero también sin reflejos condicionados." En Giovanni Russo, "Il congresso internazionale di Roma. La psicoanalisi col calcolatore," Corriere della sera, 30 de Julio de 1969. 
importantes. ${ }^{54}$ Generó también profundos debates y malestar de diversas sociedades psicoanalíticas, aunque solo en Argentina llevó a una escisión de la asociación psicoanalítica oficial. ${ }^{55}$

Si bien Fachinelli fue una de las caras de la revuelta en Italia, sus posiciones, tal cual señalamos antes, nunca llegaron al extremo de fomentar una ruptura o formar un grupo disidente independiente que, según él, terminaría reproduciendo lo mismo que criticaba. ${ }^{56}$ Pero esto no quita que tuviera una serie de reflexiones bien articuladas sobre los profundos replanteos que debía hacerse el psicoanálisis. Estas se dejan ver claramente en su ponencia al congreso internacional sobre "Psicoanálisis, psiquiatría y anti-psiquiatría" organizado en Milán en diciembre de 1969. Allí, Fachinelli observaba que uno de los rasgos más sorprendentes de los últimos tiempos era el increíble crecimiento en influencia y prestigio del psicoanálisis, y la manera en que las industrias culturales y los medios lo acreditaban y lo ponían en un lugar de autoridad. Idea que explicaba con una imagen más que elocuente, "Hoy, el psicoanálisis es una especie de nebulosa en continua expansión, que tiende a penetrar en cada zona de vacío, en cada fractura de la sociedad industrial avanzada, solicitado para proveer una respuesta psicologizante que cierre aquel vacío y esconda aquella fractura" 57.

Lo que observaba Fachinelli era que, desde los medios de comunicación de masas, y otros ámbitos sociales, se expandía la valoración y el prestigio del psicoanálisis como un saber experto que pudiera explicar desde la psicología los males de la sociedad capitalista avanzada. Y que al hacerlo cumplía un rol tranquilizador, a través de respuestas que permitían administrar el malestar en términos psicológicos. Es por eso que esta expansión, que curiosamente no provenía de los ámbitos de la salud mental propiamente dicha, tenía dos consecuencias principales que le parecían claramente negativas. En primer lugar, volver más rígidas y menos creativas las formas en que se formaban los psicoanalistas y, sobre todo, empobrecer un aspecto crucial del psicoanálisis: su capacidad para proponer "una relación nueva del hombre al saber." 58 En este sentido, la incorporación del psicoanálisis en ámbitos académicos, o el creciente prestigio de las instituciones psicoanalíticas, podían reforzar nociones objetivantes de saber, demasiado académicas y burocráticas. En segundo lugar, la expansión de la "nebulosa" psicoanalítica podía expandir su rol como saber disciplinario, y como ciencia dedicada a administrar y controlar la desviación [devianza]. Es decir, consolidar el psicoanálisis como saber aplicado a la criminología, el trabajo social, la pedagogía, y múltiples formas de control social y administración de la marginalidad y la disidencia social y cultural. ${ }^{59}$

Para Fachinelli, estas tendencias llevaban al psicoanálisis a reforzar su posición de lugar de un supuesto saber, y de proveedor de respuestas y explicaciones. Pero esto solo era posible si se negaba la "gran crisis conceptual" que aquejaba al psicoanálisis. ${ }^{60}$ Retomando sus planteos sobre el rol de la autoridad en el capitalismo avanzado, Fachinelli observaba que las realidades de la familia y las formas

\footnotetext{
54 Tanto en congreso de la IPA como el contra-congreso fueron cubiertos por, al menos, el Corriere della sera, lo cual indica el impacto del evento: ver "Il congresso di Roma. Contestazione nella psicoanalisi" Corriere della sera, 31 de Julio de 1969; "Oggi si conclude il congresso di Roma. Cauta la psicoanalisi coi bimbi," Corriere della Sera, 1 de Agosto de 1969; "Aria di contestazione al congresso internazionale di Roma. Il psicoanalista in ansia," Corriere della sera, 2 de Agosto de 1969. Sobre su impacto, ver Michel David, op cit; y Luciano Mecacci, Psicologia e psicoanalisi nella cultura italiana del Novecento, Bari, Laterza, 1998, $77-78$.

55 Para un ejemplo de las reacciones entre los psicoanalistas italianos, ver Davide Lopez, Análisis del carácter y emancipación: Marx, Freud, Reich, Madrid: Ediciones Castilla, 1971 [edición italiana de 1970]. Para el impacto de Plataforma en Argentina, ver Mariano Plotkin, Freud en las Pampas: Orígenes y desarrollo de una cultura psicoanalitica en la Argentina, 1910-1983, Buenos Aires, Sudamericana, 2003, 301-312. Para un análisis del impacto internacional del congreso del 69, ver Dagmar Herzog, Cold War Freud: Psychoanalysis in an Age of Catastrophes, Cambridge, Cambridge University Press, 2017, 213-215.

56 Ver sus posiciones en la entrevista con Sergio Benvenuto, "Sull'imposibile formazione degli analisti Conversazione con Elvio Fachinelli," Conci y Marchioro, op. cit, 207-209.

${ }^{57}$ Elvio Fachinelli, "Che cosa chiede Edipo alla sfinge?” en Elvio Fachinelli, Il bambino delle uova d'oro, Milán: Feltrinelli, 1974, 147.

58 Ibid, 148.

59 Ibid, 148-150.

${ }^{60} \mathrm{Ibid}, 153$.
} 
de autoridad en la época de Freud habían cambiado profundamente con respecto a las actuales. Y fundamentalmente, que la socialización y la incorporación de valores y modelos de personalidad ya no se daban en el marco del modelo familiar burgués tardo-victoriano que había servido de marco a las conceptualizaciones freudianas. Por el contrario, las formas de familia y los procesos de socialización del individuo en la sociedad capitalista, proponía nuevos desafíos teóricos y conceptuales, que volvían caducas las nociones más esquemáticas del modelo edípico freudiano. Solo se podían mantener reforzando las actitudes de reverencia con respecto a la herencia freudiana, el fetichismo a la letra de Freud, o la represión de los aspectos sociales que encuadran la práctica del análisis. ${ }^{61}$

En este punto Fachinelli hacía entrar el tema de la "contestación juvenil global" que se había evidenciado desde el año anterior. Y lo hacía con el objetivo de observar que el tipo de malestar difundido por la protesta estudiantil y juvenil revelaba situaciones y realidades que escapaban a las conceptualizaciones y las metodologías del análisis clásico. Fundamentalmente, Fachinelli consideraba que había que poner más énfasis en los mecanismos de incorporación del individuo a la sociedad de masas, y cómo eso debía generar una actitud muy diferente a la de los psicoanalistas tradicionales y, sobre todo, a su postura de dar respuestas en función de sus viejos conceptos. En contra de esta actitud, el psicoanálisis debía buscar un nuevo lugar desde el cual plantearse nuevas preguntas, o como lo planteaba Fachinelli, "hace falta (...) que el analista constituya en otros lugares las condiciones, posibilidades y el lenguaje de la interrogación analítica." ${ }^{2}$ Si bien no tenía una idea del todo acabada de cuáles eran estos lugares, su proyecto era bastante claro,

La escucha analítica debe manifestarse en primer lugar como capacidad de percibir lo negativo, lo irregular, lo arrítmico, las situaciones que, apenas mencionadas o aludidas, cualesquiera que sean, corren el riesgo de ser sofocadas o, mejor, encuadradas y funcionalizadas (...); debe sin embargo también manifestarse como capacidad y posibilidad de interrogar las tentativas que, muchas veces de manera rústica, elemental, desordenada, vienen continuamente surgiendo en la nueva generación como respuesta a nuevos problemas. ${ }^{63}$

Para Fachinelli, esto se podía dar mediante la intervención en instituciones educativas (como los jardines de infantes en los que se había comprometido), o el análisis de grupo, o todos los intentos por desentrañar las lógicas institucionales que enmarcaban la circulación de saberes y prácticas. Se trataba de tareas que llevaban al psicoanalista a interrogar realidades desde un saber que era también interrogado, y que lo obligaba a salir del confort del consultorio y el tratamiento individual para interactuar más con otras miradas como la de los psicólogos, antropólogos y sociólogos. Caso contrario, los psicoanalistas iban a quedar en verse socialmente beneficiados y bien tratados por los agentes culturales de la moderna sociedad de masas, pero ciegos frente a las condiciones históricas que los estaban erigiendo en interlocutores privilegiados.

Más allá de este planteo específico, los años siguientes fueron moldeando la figura de Fachinelli como un psicoanalista incómodo, en el sentido de mantenerse a contrapelo de las grandes instituciones, así como a una distancia cauta de las escisiones y nuevas organizaciones vinculadas a las iniciativas de los lacanianos y otros rebeldes. ${ }^{64}$ Se negó entonces a volverse un psicoanalista didacta de la SPI, pero al mismo tiempo siguió siendo parte de la misma, publicando libros y casos clínicos. Su figura de intelectual público se volvió también más prominente, vinculado a su editorial y revista, e interesado en cruzar lo clínico con lo cultural. También continuó escribiendo artículos para revistas como Quaderni Piacentini en los que discutía con versiones ortodoxas del marxismo, o problematizando el fervor

\footnotetext{
61 Ibid, 152.

62 Ibid, 155.

63 Ibid, 155-156.

64 Sobre el panorama del psicoanálisis italiano en los 70s, incluyendo la postura de Fachinelli, ver Michel David, "La psychanalyse;" David, La psicoanalisi nella cultura italiana, Turín, Borinhieri, 1990, pp. 605-616; y Silvia Vegetti Finzi, Storia della psicoanalisi, Milan, Mondadori, 1986, p. 262-265.
} 
acrítico hacia China y el maoísmo. ${ }^{65}$ Encontramos su nombre en iniciativas originales, como sus comentarios al libro de fotos de personas trans-género a cargo de la fotógrafa Lisetta Carmi. ${ }^{66}$ En todos estos casos, mantuvo un perfil similar al de sus ensayos en torno al '68, buscando generar una intervención intelectual a partir de piezas fugaces y polémicas, que eviten caer en formalizaciones y abstracciones que refuercen concepciones rígidas y mistificadas del saber. Esto no quita que muchos de sus juicios se hayan mantenido estables a lo largo de los años. De hecho, en entrevistas posteriores sobre el '68, no dejó de encontrar fórmulas sintéticas similares a las de sus primeros textos. Al fin y al cabo, a la hora de definir el '68, no dejó de considerarlo como "un gran enamoramiento colectivo." 67

\section{Conclusión}

Desde principio de los años '60s, el psicoanálisis en Italia experimentó un momento de auge. Si en 1964 la SPI registraba 30 psicoanalistas formados, hacia 1976 se calcula que las diversas sociedades psicoanalíticas sumaban alrededor de 400 miembros, mientras que los que no eran miembros de ninguna asociación se calculan en 800 más (David, 1982, 325-26). Se trató de un crecimiento rápido y convulsionado. Fundamentalmente, debido a que se incrementó la demanda de analistas a una velocidad que la pequeña SPI no podía reproducir. Eso generó todo tipo de acusaciones acerca de la rigidez de los itinerarios de formación, y la burocratización o comercialización de sus prácticas. No es sorprendente que los años '70s fueron el momento en que surgieron diversas sociedades psicoanalíticas alternativas, cada una de ellas escindiéndose de la SPI, y con diversos tipos de críticas teóricas y denuncias específicas. Como telón de fondo, ocurría el fenómeno de la creciente validación de los psicoanalistas ante la opinión pública. Tanto en la forma de columnistas de semanarios de circulación masiva, a través de la creación de colecciones y traducciones de bibliografía psicoanalítica, o del incremento de la demanda de psicoanalistas por parte de la población, se puede observar el cambiante estatus del psicoanálisis en Italia durante los ' 60 s. ${ }^{68}$ De una profesión más bien marginal y misteriosa pasó a ser esa "nebulosa en expansión" a la que refería Fachinelli.

Por otro lado, todo esto ocurría en un momento en que el campo de la salud mental en general estaba también en ebullición. Ya desde principios de los '60s, de hecho, habían surgido iniciativas de renovar la psiquiatría en torno a grupos que luego fundarían la revista Psicoterapia e scienze umane-y que buscaban desmarcarse tanto de la psiquiatría tradicional como del psicoanálisis ortodoxo. Pero de manera más explosiva, la experiencia en torno a Franco Basaglia en favor de eliminar los manicomios tomó creciente relevancia durante los ' 60 s, hasta transformarse en un aglutinante crucial en pos de reformas radicales de las instituciones y las profesiones de salud mental. Fue durante los ' 60 s, también, que se tradujeron al italiano autores centrales para criticar el poder psiquiátrico, tales como Ervin Goffman, David Cooper, o Ronald Laing. Al mismo tiempo, en muchos ámbitos se hicieron esfuerzos por expandir la terapia de grupo, sobre todo asociado a prácticas de auto-gestión de instituciones, o a un compromiso social de los terapeutas con población generalmente excluida del tratamiento psicoanalítico clásico. ${ }^{69}$ Que el campo de la salud mental era un espacio de combate no podía pasar desapercibido a quienes leían a autores cruciales de esos años. Sin duda Marcuse es una referencia inevitable, pero no habría que olvidar que también figuras como Frantz Fanon ponían en el centro de

\footnotetext{
${ }^{65}$ Sus principales textos durante esta época se pueden leer en su libro Fachinelli, Il bambino delle nova d'oro, op cit.

${ }^{66}$ Se trata de textos acompañando las fotos de la autora, cfr, Lisetta Carmi, I travestiti, Essedi, Roma, 1972.

${ }^{67}$ Oldrini, "la protesta sull'letino,"Conci y Marchioro, op. cit, p. 199.

68 David, “La psychanalyse;” David, La psicoanalisi nella cultura italiana, pp. 605-616; y Vegetti Finzi, op. cit, 262-265.

${ }^{69}$ Vegetti Finzi, op. cit,262-265; Donnelly, op. cit, passim; Valeria Babini, Liberi tutti: manicomi e psichiatri in Italia: una storia del Novecento, Bolonia, Il Mulino,2011; Mecacci, op. cit,, 77-82
} 
atención la psicología del colonizado, agregando una variante más a las formas de relacionar salud mental y poder. ${ }^{70}$

En este contexto, el '68 encontró al psicoanálisis en pleno proceso de crisis y de replanteo de su identidad y su lugar en la sociedad. De allí que la relación entre el psicoanálisis y los movimientos suscitados durante ese año sea más que compleja. Por un lado, el psicoanálisis, o la psicología más en general, parecía ser un espacio privilegiado para interrogar acontecimientos y fenómenos ligados a la contestación juvenil o la revuelta estudiantil. Al fin y al cabo, se trataba de expresiones juveniles de revuelta contra la autoridad, con demandas más que imprecisas disparadoras de acciones dramáticas y extremas. Algunos de los textos de Mazzetti durante esas semanas, de hecho, transparentan la voluntad de ponerse en un lugar de saber experto que analiza un objeto externo. Pero incluso si esa voluntad existió, tal ilusión duró poco. El compromiso y la comunidad con muchos de los planteos de los estudiantes re-posicionaba los textos de esta época, de manera de complicar todo intento de supuesta neutralidad u objetividad. Pero simétricamente, la opción opuesta -de compromiso total con las movilizaciones-también era imposible. No solo por las diferencias explícitas que emergían de los diferentes análisis. Sino porque incluso en los momentos de mayor adhesión a diversas iniciativas, los portadores del discurso psicoanalítico no dejaban de hacer valer un supuesto saber psicológico desde el cual validarse.

En su libro sobre el '68 en Francia, Kristin Ross propone una fórmula más que valiosa para entender el fenómeno: el hecho de que los grupos no se comportan de acuerdo a lo que se espera de ellos. 'Lo que se ha dado en llamar el 'los acontecimientos de Mayo' -sostiene la autora-consistieron mayormente en estudiantes que dejaron de funcionar como estudiantes, trabajadores como trabajadores, o granjeros como granjeros." 71 Su idea encaja muy bien para el mundo de las profesiones en Italia, o especialmente las de salud mental y el psicoanálisis. Sobre todo, en los textos de Fachinelli, las iniciativas que más lo acercaban al espíritu del momento era la que lo llevaban a cuestionar el lugar privilegiado que la moderna sociedad de masas le adjudicaba: el de saber experto que da respuestas e fenómenos específicos. Contra esta expectativa, Fachinelli buscaba elaborar un nuevo lugar desde donde posicionarse para re-pensar el psicoanálisis en la sociedad contemporánea. Se comportaba entonces de acuerdo a como Mazzetti veía a los estudiantes: como movidos por el "gran rechazo" que los llevaba a renunciar a sus privilegios como tecnócratas del orden establecido. En qué medida esto fue posible, y qué efectos contribuyó a crear es ya objeto de otro análisis. Por el momento, solo nos queda concluir resaltando la situación que parece haber sido la del psicoanálisis durante el '68: la de un espectador que no deja de ser actor $y$, viceversa, un actor que no puede dejar de contemplar.

\section{Bibliografía}

Valeria Babini, Liberi tutti: manicomi e psichiatri in Italia: una storia del Novecento, Bolonia, Il Mulino,2011

Sergio Benvenuto, "Sull'imposibile formazione degli analisti Conversazione con Elvio Fachinelli," Conci y Marchioro, op. cit

Lisetta Carmi, I travestiti, Essedi, Roma, 1972

Michel David, La psicoanalisi nella cultura italiana, Turín, Borinhieri, 1990, pp. 605-616

\footnotetext{
70 Franz Fanon, Los condenados de la tierra, Buenos Aires, FCE, 2015 [1961], pp. 228-286. Sobre la influencia de Fanon en Italia, ver Lumley, op. cit, pp. 212,289

${ }^{71}$ Ross, op. cit, p. 25.
} 
Michel David, "La psychanalyse en Italie," Roland Jaccard (ed), Histoire de la psychanalyse, vol 2, Paris, Hachette, 1982

Michael Donnelly, The Politics of Mental Health in Italy, Londres, Routledge, 1992.

Marco Conci y Francesco Marchioro (eds), Elvio Fachinelli: Intorno al '68. Una antologia di testi, Bolsena (VT), Massari Editore, 1998.

Geoff Eley, Forging Democracy: The History of the Left in Europe, 1850-2000, Nueva York, Oxford University Press, 2002.

Elvio Fachinelli, Il bambino delle nova d'oro, Milán: Feltrinelli, 1974

Elvio Fachinelli, Luisa Muraro Valani, y Giuseppe Sartori (eds), L'erba voglio: Pratica no autoritaria nella scuola, Turín, Einaudi, 1971

Franz Fanon, Los condenados de la tierra, Buenos Aires, FCE, 2015 [1961]

David Forgacs, L’industrializzarione della cultura italiana (1880-2000), Bolonia, Il Mulino, 1992

Ronald Fraser (ed), 1968: A Student Generation in Revolt, Nueva York, Pantheon Books, 1988

Sigmund Freud, "Totem y tabú: algunas concordancias en la vida anímica de los salvajes y los neuróticos," en Sigmund Freud, Obras completas, vol. 13, Buenos Aires, Amorrortu, 2012.

Diego Giachetti, Anni Sessanta Comincia la Danza. Giovani, Capeloni, Studenti ed Estremisti negli Anni della Contestazione, Pisa, BFS, 2002.

Paul Ginsborg, A History of Contemporary Italy. Society and Politics, 1943-1988, Nueva York, Palgrave, 2003

Stephen Gundle, Between Hollywood and Moscow: The Italian Communists and the Challenge of Mass Culture, 1943-1991, Durham, Duke University Press, 2000

Dagmar Herzog, Cold War Freud: Psychoanalysis in an Age of Catastrophes, Cambridge, Cambridge University Press, 2017

Tony Judt, Postwar: A History of Europe since 1945, Nueva York, Penguin Press, 2005.

Martin Klimke y Joachim Scharloth (eds), 1968 in Europe: A History of Protest and Activism, Nueva York, Palgrave, 2008

Jan Kurz y Marica Tolomeli, “Italy,” en Klimke y Scharloth (eds), op. cit, 87-89

Davide Lopez, Análisis del carácter y emancipación: Marx, Freud, Reich, Madrid: Ediciones Castilla, 1971

Robert Lumley, States of Emergency: Cultures of Revolt in Italy from 1968 to 1978, Londres, Verso, 1990

Herbert Marcuse, Eros and Civilization, Nueva York:, Vintage, 1955. 
Luciano Mecacci, Psicologia e psicoanalisi nella cultura italiana del Novecento, Bari, Laterza, 1998

Ben Mercer, "The Paperback Revolution: Mass-circulation of Books and the Cultural Origins of 1968 in Western Europe," Journal of the History of Ideas, vol 72, n 4 (Octubre 2011).

Mauro Pasqualini, "Psychoanalysis to the People! Alienation, Anguish, and the Unconscious in a Review of the Italian Left, 1961-1969," Psychoanalysis and History, 15:1, Enero 2013.

Luisa Passerini, Autoritratto di gruppo, Florencia, Giunti, 1988

Mariano Plotkin, Freud en las Pampas: Orígenes y desarrollo de una cultura psicoanalítica en la Argentina, 19101983, Buenos Aires, Sudamericana, 2003

Kristin Ross, May '68 and its Afterlives, Chicago, University of Chicago Press, 2002.

Donald Sasoon, One Hundred Years of Socialism: The West European Left in the Twentieth Century, Londres, Fontana, 1993.

Silvia Vegetti Finzi, Storia della psicoanalisi, Milan, Mondadori, 1986, p. 262-265.

\section{Publicaciones Periódicas}

Vie Nuove

Quaderni Piacentini

Corriere della Sera 